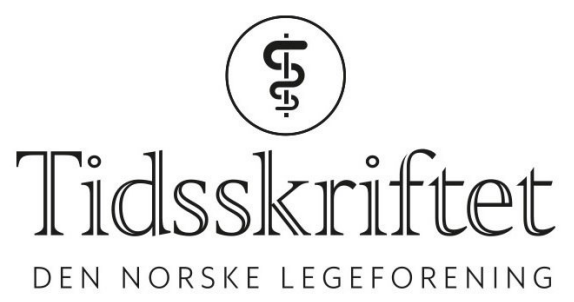

\title{
Onkoplastisk brystbevarende kirurgi
}

KLINISK OVERSIKT

\section{CHRISTIAN KORVALD}

E-post: ckorvald@ous-hf.no

Avdeling for plastikk- og rekonstruktiv kirurgi

Oslo universitetssykehus, Rikshospitalet

Christian Korvald er dr.med., spesialist i plastikkirurgi og overlege. Han er medlem av NBCG (Norsk brystcancergruppe) og NBCGs arbeidsgruppe for brystrekonstruksjon.

Forfatteren har fylt ut ICMJE-skjemaet og oppgir ingen interessekonflikter.

\section{INGER CHRISTINE L'ORANGE}

Seksjon for bryst- og endokrinkirurgi Avdeling for kreftbehandling Oslo universitetssykehus, Aker sykehus

Inger Christine L'orange er master i onkoplastisk kirurgi, spesialist i generell kirurgi og i bryst- og endokrinkirurgi og overlege.

Forfatteren har fylt ut ICMJE-skjemaet og oppgir ingen interessekonflikter.

Onkoplastisk brystbevarende kirurgi utvider indikasjonen for brystbevarende kirurgi. Med onkoplastiske teknikker omformes eller erstattes vev i brystet samtidig med kreftkirurgien for å bibeholde livskvalitet og et naturlig bryst som også tolererer nødvendig etterbehandling. Onkologisk anses denne behandlingen som trygg sammenlignet med tradisjonell brystbevarende kirurgi og mastektomi.

Brystkreft behandles kirurgisk enten ved å fjerne selve svulsten og bevare resten av brystet, eller ved å fjerne hele brystkjertelen. Begge deler kan være mutilerende for pasienten, men likevel er brystbevarende kirurgi å foretrekke så lenge radikal fjerning av kreftvev oppnås.

Halsteds radikale mastektomi fra 1894, med senere modifikasjoner, har vært rådende behandling av brystkreft inntil slutten av forrige århundre. Teknikken har vært beheftet med betydelig morbiditet, spesielt lymfødem i armen. I dag har god og tidlig bildediagnostikk, målrettede vevsprøver, vaktpostlymfeknuteteknikk som sparer lymfeknuter i armhulen, og stadig bedret kjemoterapi gjort at man langt oftere kan tilby mindre omfattende kirurgi. Hos majoriteten av kvinner med nydiagnostisert brystkreft vil brystbevarende kirurgi være anbefalt og trygg behandling (1). På landsbasis ble $82 \%$ av all brystkreftkirurgi for svulster med diameter mindre enn $30 \mathrm{~mm}$ utført brystbevarende i 2018 (2). Neoadjuvant kjemoterapi sparer også mange kvinner for mastektomi selv om de hadde store svulster initialt $(3,4)$. På tross av betydelig lavere postoperativ morbiditet kan brystbevarende kirurgi medføre problemer i det opererte brystet, som for eksempel fastsittende, smertefullt arr, manglende volum og asymmetri med motsatt, frisk side (figur 1). Mye av dette kan skyldes adjuvant stråleterapi, som de aller fleste gjennomgår (4), men det kan også bero på undervurdering av svulstens volum i forhold til bryststørrelse og svulstens lokalisasjon i brystet (5). «Enkel» brystbevarende kirurgi, der man fjerner svulsten 


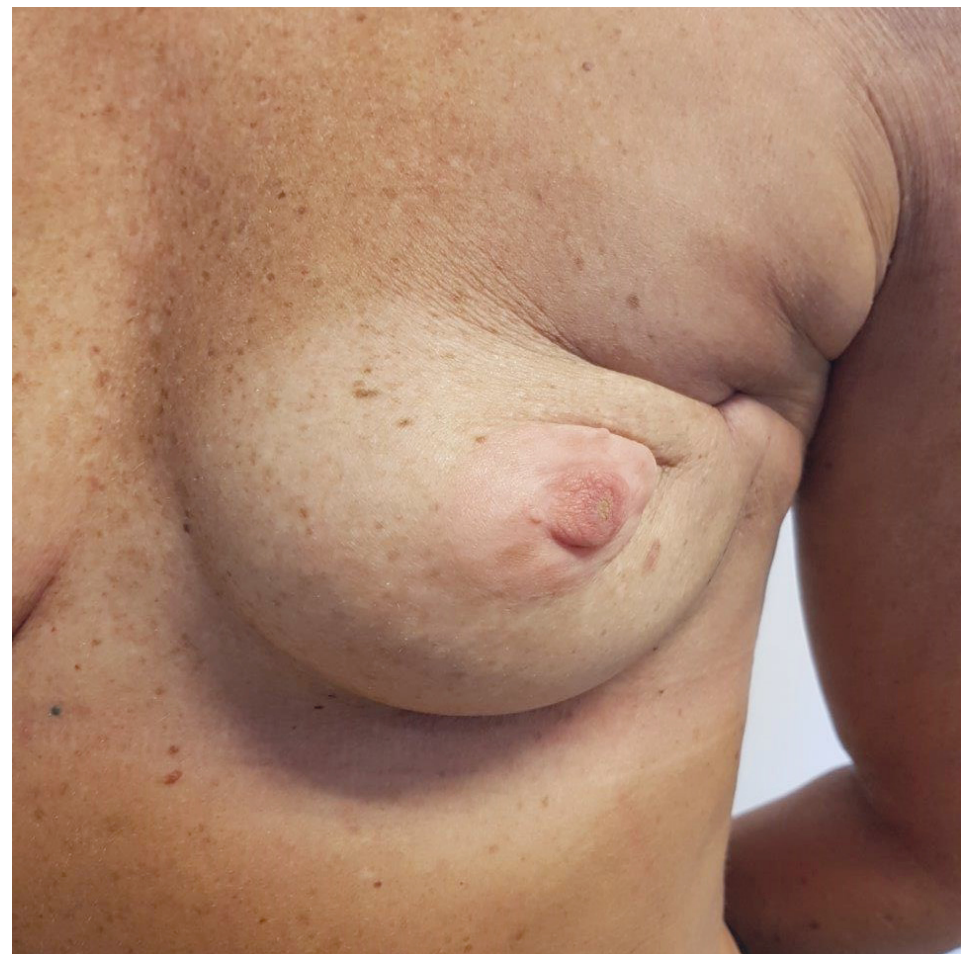

Figur 1 Resultat etter brystbevarende kirurgi av tumor i øvre laterale del av venstre bryst med påfølgende strålebehandling. Brystvorten er trukket inn mot vevsdefekten som følge av arrskrumpning. Onkoplastisk teknikk ble ikke benyttet.

Onkoplastisk brystbevarende kirurgi er utviklet for å unngå de negative sidene ved enkel brystbevarende kirurgi, samtidig som man opprettholder onkologisk sikkerhet (5-7). Onkoplastikk handler - slik navnet, som er avledet av gresk onkos 'svulst' og plastikos 'formbar', antyder - om å fjerne svulsten og samtidig omforme eller erstatte vev i brystet. Målet er å minimere arrdannelse og gjøre vevet mer robust for etterbehandling, og på den måten bevare livskvalitet og kosmetisk utseende. I sin videste forstand kan dette handle om alt fra hvordan man får et lavt, pent arr med en jevn huddekning som tolererer ekstern protese godt, til avansert total brystrekonstruksjon med protese eller fri mikrokirurgisk hud- og fettlapp. Det kan også handle om å ta hensyn til anatomi i forbindelse med mastektomi slik at forholdene for rekonstruksjon blir optimale, eller å gjøre brystreduksjon samtidig med at svulsten fjernes. I tillegg gjør onkoplastiske teknikker oss i stand til å fjerne større deler av brystet enn tidligere og samtidig få et godt kosmetisk resultat. Vi gir her en oversikt over onkoplastisk brystbevarende kirurgi basert på egne kliniske erfaringer og utvalgt faglitteratur. Primær rekonstruksjon med silikonproteser eller frie mikrokirurgiske hud- og fettlapper omtales ikke.

\section{For hvem?}

Alle pasienter, uansett alder (5), som er diagnostisert med brystkreft, bør vurderes som kandidater for onkoplastisk brystbevarende kirurgi (4).

Størrelsen på en kreftsvulst har, sammen med stadieinndeling, krefttype og tumorbiologi, betydning for hvilken type behandling kvinnen vil få for sin kreftsykdom (4). Under planlegging av kirurgien må man vurdere svulstens størrelse opp mot hele brystet, siden fjerning av 10-20\% av totalt brystvolum kan gi endringer i form og volum som kvinner flest anser som utilfredsstillende (5). Dette avhenger av hvor i brystet svulsten er lokalisert, da fjerning av $15-20$ \% i øvre laterale kvadrant kan gi et tilfredsstillende resultat, mens 5-10 \% i nedre mediale kvadrant kan gi en uttalt deformitet ved enkel brystbevarende kirurgi.

Figur 2 viser hvor stort volum brystvev (i prosent) man må forvente å fjerne ved forskjellige tumorstørrelser (diameter 1-5 cm) som funksjon av brystets totalvolum (4). Diagrammet kan brukes til grovt å antyde hvilken metode som er best egnet til å reparere defekten $\mathrm{i}$ 
brystet etter at svulsten er fjernet (5). Samme størrelse og lokalisering av en svulst vil således kunne lede til enten enkel brystbevarende eller onkoplastisk kirurgi i henholdsvis stort og lite bryst.

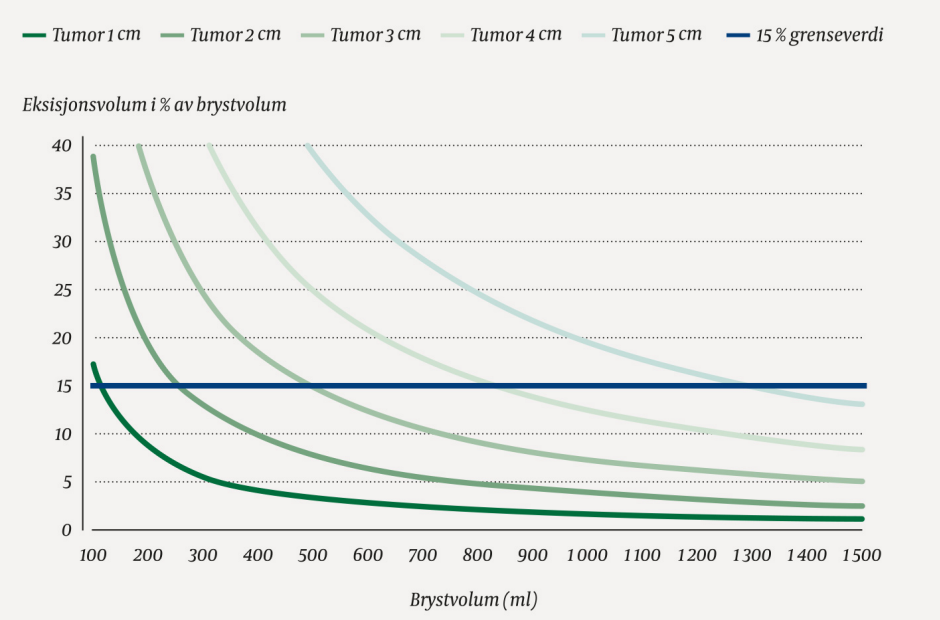

Figur 2 Prosentvis andel av hele brystet man må forvente å fjerne ved ulike tumorstørrelser. Kurvene representerer svulster med diameter fra 1 til $5 \mathrm{~cm}$. Svulsten er tenkt som en kule med $1 \mathrm{~cm}$ tillagt omkringliggende kirurgisk sikkerhetsmargin. Ved fjerning av større andel enn $15 \%$ av brystet (horisontal strek) bør onkoplastiske teknikker vurderes preoperativt.

Kvinnens ønsker og oppfattelse av egen kropp bør være med på å lede valg av behandlingsalternativ. Lever hun godt med brystet slik det er i dag? Har hun plager på grunn av tunge bryst? Skjemmes hun av at kjertelvev har seget ned og strukket ut huden? Hvilke og hvor lange arr kan hun akseptere? Hvilken grad av aktivitet er hun avhengig av? Individuelle tilpasninger bør klarlegges i den preoperative samtalen og følges opp gjennom den rekonstruktive prosessen. Eksempelvis vil en liten kreftsvulst $i$ et stort bryst «enkelt» behandles med lokal eksisjon, mens bilateral reduksjonsplastikk er en bedre behandling dersom kvinnen samtidig sliter med tyngdesymptomer fra hypertrofe bryst (se figur 3). En annen kvinne kan ønske å bevare volumet i det syke brystet og samtidig bevare brystet på motsatt side urørt. Vev kan da tilføres i stedet for å omforme det, slik vi ser i figur 4 .

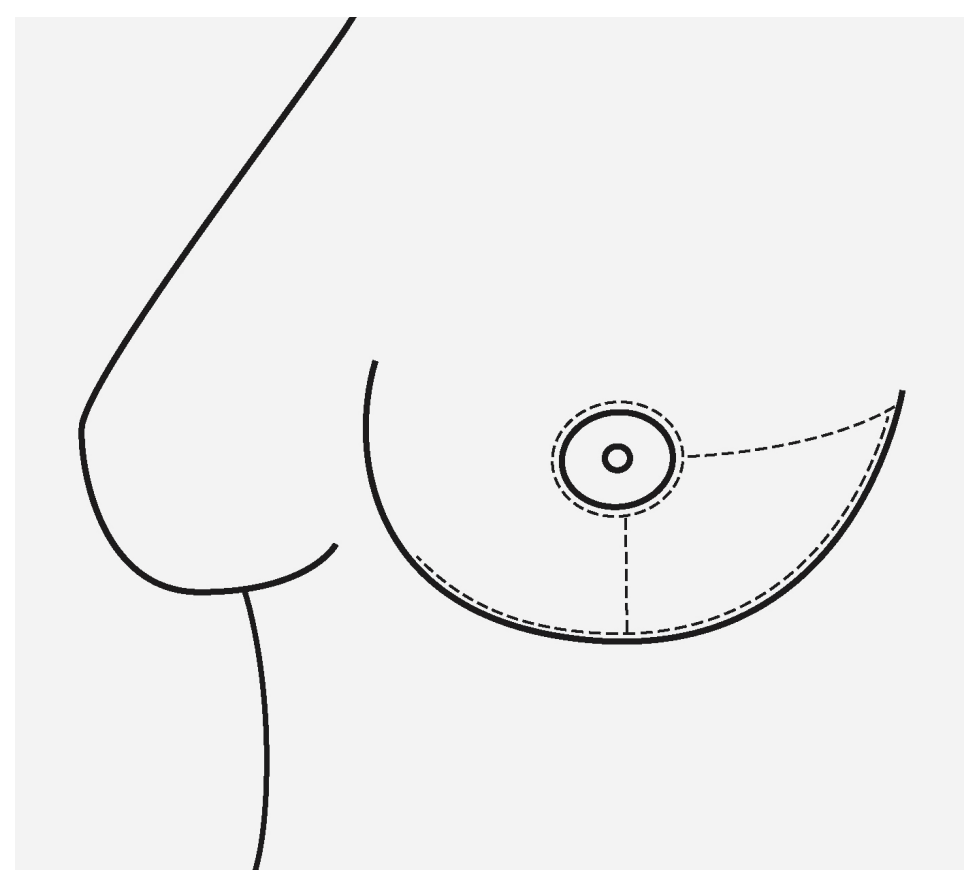

Figur 3 Incisjonslinjer som harmoniserer med onkoplastiske teknikker, og som vil kunne skjules godt $i$ etterkant. 


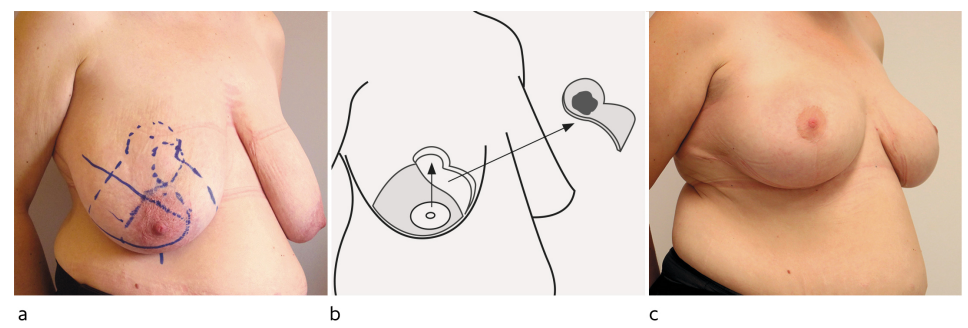

Figur 4 Onkoplastisk brystreduksjon med symmetrisering av motsatt side. a) Før operasjon. Svulsten er markert med prikket sirkel. b) Svulst og resektat er tatt ut i én bit. Lappen av hud- og brystvev som bcerer brystvorten, roteres opp og inn i defekten, og hudkanter sys mot hverandre. c) Postoperativt resultat to år etter endt strålebehandling.

\section{Hvordan?}

Snittføring er viktig i et onkoplastisk perspektiv. Et kirurgisk snitt skjules best i hudfolder og pigmentoverganger, f.eks. rundt areola. Enhver svulst i brystkjertelen kan fjernes via incisjoner enten periareolært, radiært lateralt eller kaudalt fra areola eller i inframammærfuren (se figur 5) (8). Annen snittføring bør etter vår mening unngås fordi arrene blir vanskeligere å skjule, senere reeksisjon eller mastektomi med behov for onkoplastikk eller annen rekonstruksjon kan bli vanskeligere, og hudsirkulasjonen kan kompromitteres.

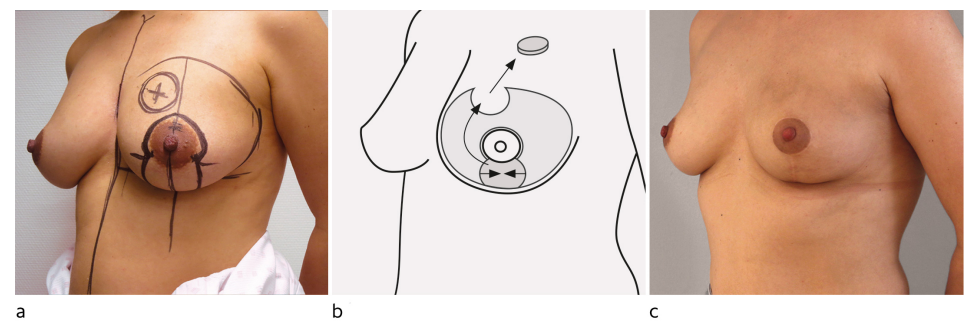

Figur 5 Onkoplastisk brystløft. Kun venstre bryst er operert. a) Før operasjon. Svulsten ligger oppad medialt i brystet og er markert med sirkel med kryss. Hud fjernes mellom strekene nedenfor brystvorten. b) Hud undermineres medialt slik at mediale del av brystkjertelen kan roteres inn $i$ defekten etter svulsten. De vertikale hudkantene sys mot hverandre og lukker såret etter hudfjerning. c) Resultat fjorten måneder etter operasjon og seks måneder etter strålebehandling.

Gjør man enkel brystbevarende kirurgi, kan det likevel være påkrevet å samtidig gjøre en enklere plastikk omkring areola for å korrigere for forventede arrforandringer. Halvmåne-, flaggermusvinge- og smultringplastikk er eksempler på dette og er i mange publikasjoner benevnt som onkoplastiske «nivå 1-prosedyrer» (9). Disse prosedyrene omtales ikke nærmere her.

Mer avansert onkoplastisk kirurgi blir aktuelt ved større reseksjoner og baserer seg på plastikkirurgiske teknikker som reduksjonsplastikk, brystløft (mastopeksi) eller flytting av hud- og fettlapper (5). Hovedforskjellen mellom en brystreduksjon og et brystløft er mengden vev som fjernes. I mange publikasjoner er disse teknikkene benevnt som «nivå 2prosedyrer» (9).

\section{Onkoplastisk brystreduksjon}

Forskjellige teknikker for reduksjonsplastikk følger bestemte mønster for hudsnitt og uttak av fett- og kjertelvev, og planlegges i onkoplastisk sammenheng slik at svulsten kan følge med i resektatet. Blodsirkulasjon til brystvorten bevares gjennom egne hud- og kjertellapper, avhengig av teknikk (10). En kvinne med relativt store bryst (> $700 \mathrm{ml})$ der svulsten ligger innenfor planlagt resektat og som samtidig ønsker og aksepterer redusert brystvolum og løfting av brystet, er kandidat for slik behandling (figur 3) (5). Snittføring ved slike inngrep vil vanligvis resultere i arr tilsvarende det vi kaller «ankersnitt» (figur 3)(8). I tilfeller der svulsten er lokalisert utenfor vanlig mønster for reduksjonsplastikk, må man 
improvisere med utformingen av både hud-, kjertel- og areola-mamillelappene for å fylle defekten etter uttak av tumoren. I ekstra store bryst benyttes også varianter av kileeksisjon uten å bevare brystvorten (10). Det viktigste er at man ved disse teknikkene gjør vid eksisjon av svulsten med kjertelvev og dermed oppnår gode marginer til kreftforandringene (11). Samtidig med at det syke brystet opereres, tilbys en symmetriserende reduksjonsplastikk på det andre brystet, slik at pasienten kan unngå behov for ytterligere kirurgi.

\section{Onkoplastisk brystløft}

Kvinner som har middels store bryst (400-70o ml), helst med en viss grad av nedfall av kjertelvev (ptose) og samtidig hudoverskudd, vil ofte kunne bli tilbudt et brystløft (se figur 6) som ledd i behandlingen $(5,10,12)$. Som følge av at svulsten fjernes, må hun akseptere at brystvolumet blir lettere redusert. Til forskjell fra en reduksjonsplastikk fjernes kun svulsten med god margin til friskt vev. Resterende vev vil ved et onkoplastisk brystløft vanligvis roteres for å lukke defekten etter svulsten med samtidig korreksjon av overskuddshud. Blodforsyning til brystvorten sikres enten direkte fra samme vevslapp, som roteres, eller fra en sekundær subkutant basert lapp. Her tilbyr man også vanligvis et symmetriserende inngrep i samme operasjon.

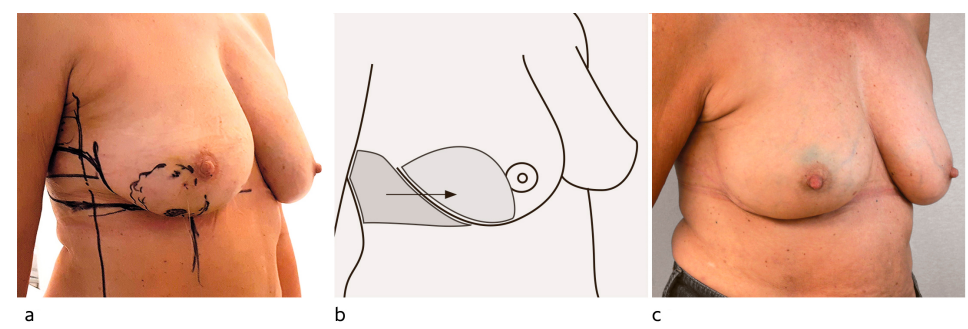

Figur 6 Erstatningsplastikk. Kun høyre side er operert. a) Stor tumor i nedre laterale kvadrant av høyre bryst (stiplet sirkel), som medfører fjerning av rundt $25 \%$ av brystets volum. b) Defekten $i$ brystet og LICAP-lapp som hentes fra toraksveggen lateralt. Overflatehud fjernes fra LICAP-lappen, som deretter foldes inn i brystet. c) Resultat seks måneder etter operasjon og tre måneder etter endt stråleterapi.

\section{Erstatning av vev}

I små og middels store bryst (volum 100-70o ml) med relativt stor svulst vil ikke kjertelplastikk være tilstrekkelig for å lukke defekten etter reseksjon av svulsten. I slike tilfeller kan en hud- og fettlapp fra brystets omgivelser brukes som vevserstatter $(5,13)$.

Hud- og fettlapper trenger blodforsyning. Fra torakale aorta går det interkostale kar ut mellom hvert ribben som avgir perforerende grener til subkutant vev på brystkassen (intercostal artery perforator, ICAP), store nok til å forsyne relativt store hud- og fettlapper. ICAP-lappene kan fylle defekter i nedre og laterale del av brystet og kategoriseres etter lokalisering av perforatorene: medial (MICAP), anterior (AICAP) eller lateral (LICAP). Epitelet fjernes, og hele lappen foldes eller roteres og begraves inni brystet. En LICAP-lapp kan høstes i opp mot 30 centimeters lengde og kan bidra med betydelig volum, spesielt lateralt i brystet (figur 4). Teknikken gir ingen arr på selve brystet, siden incisjonen legges $\mathrm{i}$ folden under brystet og eventuelt ut lateralt på brystkassen, der det kan skjules av en BH.

Defekter i øvre og mediale deler av brystet er vanskeligere å fylle med ICAP-lappene. Lapper basert på perforatorer fra arteria thoracica lateralis (lateral thoracic artery perforator, LTAP) eller arteria thoracodorsalis (thoracodorsal artery perforator, TDAP) er da alternativer. Disse kan nå alle deler av brystet eller eventuelt erstatte hele brystkjertelen. Tidkrevende disseksjon av perforator gjennom musculus latissimus dorsi med samtidig bevart motornerve begrenser rutinemessig bruk av TDAP-lappen, men kan gjøres raskere dersom deler av eller hele m. latissimus dorsi og motornerve ofres samtidig (13). 


\section{Forsinket onkoplastikk}

Manglende fri margin til kreftvev etter første operasjon kan forekomme og leder da til anbefaling om ny operasjon for å sikre frie kanter. Pasienter med utbredt duktalt karsinom in situ (DCIS), invasiv lobulær brystkreft eller mer uklart avgrensede svulster gjennomgår oftere rereseksjon. I slike tilfeller kan det derfor være lurt å utsette den rekonstruktive prosedyren til histologisk undersøkelse er ferdig (etter 2-4 uker) og man har sikret en fri margin, siden området hvor svulsten satt, kan være vanskeligere å definere i etterkant, og selve rekonstruksjonen kan gå tapt. Tomrommet etter svulsten holdes åpent i ventetiden ved å fylle det med sterilt vann og lukke hud vanntett over. Brystplastikken fullføres så i en ny operasjon, samtidig med en eventuell utvidet eksisjon (5).

\section{Diskusjon}

Onkoplastisk brystbevarende kirurgi må ikke gå på bekostning av nødvendig onkologisk behandling. Studier viser at onkoplastisk brystbevarende kirurgi gir like god kontroll på sykdommen sammenlignet med enkel brystbevarende kirurgi eller mastektomi om man ser på reseksjonsmargin, residiv og overlevelse $(6,7,11,14,15)$.Vi har også inntrykk av færre operative inngrep, mindre smerter og raskere rehabilitering blant våre pasienter. Hvorvidt behandlingen er kostnadseffektiv, er sparsomt dokumentert - hittil er det kun vist at onkoplastisk brystreduksjon er mer kostnadseffektivt enn subkutan mastektomi med primær implantatbasert rekonstruksjon (16).

Med tanke på eget kroppsbilde, selvopplevd utseende av operert bryst og tid borte fra jobb kommer onkoplastisk brystbevarende kirurgi bedre ut enn mastektomi med primær rekonstruksjon (14), også i de tilfellene der strålebehandling ikke hadde vært nødvendig ved valg av mastektomi (14). Et lite materiale viser også lavere grad av sårkomplikasjoner ved onkoplastisk brystbevarende kirurgi (17). I noen få tilfeller kan komplikasjoner utsette adjuvant behandling (18). Det opererte brystet vil etter onkoplastisk brystbevarende kirurgi og strålebehandling vanligvis både se og føles fastere enn brystet på motsatt side. Likevel beskrives det av kvinnene som naturlig (5). Man må på lang sikt påregne en viss grad av fettvevsnekrose eller ujevnheter (19) - noe som har lite å si for brystets form, men som kan være til bekymring for pasienten. God oppfølging og informasjon om vanlig forløp er viktig.

Til tross for det ovennevnte kan man ikke, onkologisk sett, si at onkoplastikk er bedre enn mastektomi eller standard brystbevarende kirurgi, mye grunnet mangel på større, prospektive studier. Undersøkelser som foreligger, er av retrospektiv karakter og fra enkeltstående institusjoner $(6,7,11)$. I en nyere metaanalyse av ni tidligere studier som sammenlignet onkoplastisk brystbevarende med enkel brystbevarende kirurgi, med begrenset observasjonstid, fant man signifikant lavere reeksisjonsrate og samtidig en tendens til færre lokalresidiv etter onkoplastisk brystbevarende kirurgi (evidensnivå 2a) (20).

Kvinner under 40 år anbefales såkalt boost-bestråling lokalisert til området i brystet der svulsten satt etter brystbevarende kirurgi $(4,21)$. Boost gis også til kvinner under 50 år ved mange sentre i Norge. Onkoplastisk kirurgi kan vanskeliggjøre boost-bestråling både med tanke på lokalisering og målvolum for strålebehandlingen. For å sikte inn denne strålebehandlingen best mulig settes små metallmarkører (klips) igjen i tomrommet etter svulsten. Likevel kan reseksjonsflatene være forflyttet i forhold til hverandre etter onkoplastisk rekonstruksjon og således vanskelige å tyde ved planlegging av strålebehandlingen. Derfor er nøyaktig operasjonsbeskrivelse samt bildegjennomgang og kommunikasjon med stråleonkolog av $\emptyset$ ket betydning i forbindelse med onkoplastiske prosedyrer (4, 21).

Vi har lagt oss på en noe lavere grenseverdi (>15\%) for når man skal vurdere onkoplastisk brystbevarende kirurgi i stedet for enkel brystbevarende kirurgi enn eksempelvis den som brukes i USA (> 20\%) (9). Inndelinger og grenseverdier lages for å gjøre ting enklere å forholde seg til, men vil også potensielt kunne innskrenke mulighetene for avansert 
onkoplastikk hos mange kvinner. Med lavere grenseverdier og romsligere indikasjoner tror vi på øket årvåkenhet for alle former for onkoplastisk kirurgisk behandling.

I moderne brystkreftbehandling og handlingsprogrammer har onkoplastisk brystbevarende kirurgi en sentral plass $(4,5)$. Det er flere sentre i Norge som har et godt etablert onkoplastisk tilbud til kvinner med nydiagnostisert brystkreft, mens noen er i startfasen. Det finnes dog ingen god nasjonal oversikt over tilbudet av denne typen behandling. Onkoplastisk kirurgi kan og bør registreres i Nasjonalt kvalitetsregister for brystkreft (via Kreftregisterets elektroniske meldetjeneste, KREMT) med spesifisert behandlingsvalg på et skjematisk nivå for å bedre oversikten.

\section{Konklusjon}

Målet med behandling av brystkreft er å fjerne sykdommen. Samtidig bør vi minimere de fysiske skadene av behandlingen. Onkoplastisk brystbevarende kirurgi gir en mer individualisert kirurgisk behandling av brystkreft, der kvinnens behov for et godt utseende og godt bevart livskvalitet forsøkes ivaretatt. Onkologisk sikkerhet er alltid viktigst og ivaretas også gjennom denne behandlingen.

\section{LITTERATUR:}

1. Veronesi U, Cascinelli N, Mariani L et al. Twenty-year follow-up of a randomized study comparing breast-conserving surgery with radical mastectomy for early breast cancer. N Engl J Med 2002;347: 1227-32. [PubMed][CrossRef]

2. Nasjonalt servicemiljø for medisinske kvalitetsregistere. Nasjonalt kvalitetsregister for brystkreft. https://www.kvalitetsregistre.no/registers/492/resultater Lest 2.1.2020.

3. Schaverien MV, Raine C, Majdak-Paredes E et al. Therapeutic mammaplasty-extending indications and achieving low incomplete excision rates. Eur J Surg Oncol 2013;39:329-33. [PubMed][CrossRef]

4. Norsk bryst cancer gruppe. Retningslinjer brystkreft. https://nbcg.no/retningslinjer/ Lest 2.1.2020.

5. Macmillan RD, McCulley SJ. Oncoplastic breast surgery: What, when and for whom? Curr Breast Cancer Rep 2016; 8: 112-7. [PubMed][CrossRef]

6. Mansell J, Weiler-Mithoff E, Stallard S et al. Oncoplastic breast conservation surgery is oncologically safe when compared to wide local excision and mastectomy. Breast 2017;32:179-85.

[PubMed][CrossRef]

7. De La Cruz L, Blankenship SA, Chatterjee A et al. Outcomes after oncoplastic breast-conserving surgery in breast cancer patients: A systematic literature review. Ann Surg Oncol 2016; 23:3247-58. [PubMed][CrossRef]

8. Frey JD, Salibian AA, Levine JP et al. Incision choices in nipple-sparing mastectomy: A comparative analysis of outcomes and evolution of a clinical algorithm. Plast Reconstr Surg 2018; 142: 826e-35e. [PubMed][CrossRef]

9. Chatterjee A, Gass J, Patel K et al. A consensus definition and classification system of oncoplastic surgery developed by the American Society of Breast Surgeons. Ann Surg Oncol 2019; 26: 3436-44. [PubMed][CrossRef]

10. Macmillan RD, James R, Gale KL et al. Therapeutic mammaplasty. J Surg Oncol 2014; 110: 90-5. [PubMed][CrossRef]

11. Clough KB, van la Parra RFD, Thygesen $\mathrm{HH}$ et al. Long-term results after oncoplastic surgery for breast cancer: A 10-year follow-up. Ann Surg 2018; 268: 165-71. [PubMed][CrossRef]

12. Piper M, Peled AW, Sbitany H. Oncoplastic breast surgery: current strategies. Gland Surg 2015; 4 : 154-63. [PubMed]

13. Hamdi M. Oncoplastic and reconstructive surgery of the breast. Breast 2013; 22 (suppl 2): S100-5. [PubMed][CrossRef]

14. Kelsall JE, McCulley SJ, Brock L et al. Comparing oncoplastic breast conserving surgery with 
mastectomy and immediate breast reconstruction: Case-matched patient reported outcomes. J Plast Reconstr Aesthet Surg 2017; 70: 1377-85. [PubMed][CrossRef]

15. Bali R, Kankam HKN, Borkar N et al. Wide local excision versus oncoplastic breast surgery: Differences in surgical outcome for an assumed margin (o, 1, or $2 \mathrm{~mm}$ ) distance. Clin Breast Cancer 2018; 18: e1053-7. [PubMed][CrossRef]

16. Asban A, Homsy C, Chen L et al. A cost-utility analysis comparing large volume displacement oncoplastic surgery to mastectomy with single stage implant reconstruction in the treatment of breast cancer. Breast 2018; 41: 159-64. [PubMed][CrossRef]

17. Crown A, Scovel LG, Rocha FG et al. Oncoplastic breast conserving surgery is associated with a lower rate of surgical site complications compared to standard breast conserving surgery. Am J Surg 2019; 217: 138-41. [PubMed][CrossRef]

18. Hillberg NS, Meesters-Caberg MAJ, Beugels J et al. Delay of adjuvant radiotherapy due to postoperative complications after oncoplastic breast conserving surgery. Breast 2018; 39: 110-6. [PubMed][CrossRef]

19. Amitai Y, Golan O, Barnea Y et al. Follow-up of patients undergoing oncoplastic surgery - more palpable masses and benign biopsies. Breast Dis 2018; 37: 115-21. [PubMed][CrossRef]

20. Chen JY, Huang YJ, Zhang LL et al. Comparison of oncoplastic breast-conserving surgery and breastconserving surgery alone: A meta-analysis. J Breast Cancer 2018; 21:321-9. [PubMed][CrossRef]

21. Shah C, Al-Hilli Z, Schwarz G. Oncoplastic surgery in breast cancer: Don't forget the boost! Ann Surg Oncol 2018; 25: 2509-11. [PubMed][CrossRef]

Publisert: 24. februar 2020. Tidsskr Nor Legeforen. DOI:10.4045/tidsskr.19.0371

Mottatt 27.5.2019, første revisjon innsendt 11.9.2019, godkjent 2.1.2020.

(C) Tidsskrift for Den norske legeforening 2020. Lastet ned fra tidsskriftet.no 